
\title{
28 Research Suare \\ Contemporary public image of the nursing profession in Saudi Arabia
}

\section{Hala Elmorshedy ( $\nabla$ elmorshedyh@hotmail.com )}

Princess Nourah bint Abdulrahman University College of Medicine https://orcid.org/0000-0002-25745629

Abrar AlAmrani

King Fahd Medical Research Center

Mona Ahmed Hassan

Alexandria University

\section{Susan Ann Albrecht}

University of Pittsburgh

\section{Research article}

Keywords: Nursing profession; Perception; Knowledge; Saudi Arabia.

Posted Date: November 19th, 2019

DOI: https://doi.org/10.21203/rs.2.17447/v1

License: (1) (1) This work is licensed under a Creative Commons Attribution 4.0 International License. Read Full License

Version of Record: A version of this preprint was published at BMC Nursing on June 9th, 2020. See the published version at https://doi.org/10.1186/s12912-020-00442-w. 


\section{Abstract}

Background In the Kingdom of Saudi Arabia, the nursing profession faces significant challenges including failure to recruit high school students into nursing education; poor nursing identity, and lack of awareness about the nursing profession. Exploring the level of awareness about the nursing profession and Understanding factors that influence the nursing image is crucial for planning effective intervention programs to recruit and retain students into nursing education, and to improve nurses' sense of identity.Methods The purpose of the present study was to explore the public image of the nursing profession. A descriptive cross-sectional study included 502 adults; 106 males and 396 females, their mean age was $22.93 \pm 6.76$ years. Data collected included; socio-demographic data, gender preference in getting nursing care, knowledge, and perceived barriers to pursue a nursing career. Data were analyzed using SPSS version 21.0.Results Only 32.5\% preferred to get nursing care by Saudis. The nursing profession was not viewed as a respected job as $71.5 \%$ of participants would be ashamed of having a nurse in their families. The study revealed a low median knowledge score (50.0, IQR: 50.0-66.7)). The study highlighted a number of sociocultural barriers to pursue a nursing career: the mixed working environment (35.9\%), delayed marriage of female nurses $(20.3 \%)$, and the negative effect of nursing profession on social life (64.5\%). Conclusion Poor knowledge and sociocultural perceived barriers are the main factors contributing to the negative public image of the nursing profession in Saudi Arabia. The findings of our study will help to implement effective strategies to modify the negative perception and raise community awareness about the nursing profession.

\section{Background}

The shortage of nurses is a growing problem world-wide [1-4]. Many developed countries as Australia, Canada, the UK, and the USA have undergone cycles of nursing shortages [5]. The problem is predicted to reach a crisis with negative consequences on the health care systems and patients' safety $[6,7]$.

In view of the current situation of the nursing shortage, some countries have turned to international recruitment solutions. However, the international spatial movement of nursing labor may result in delivering inappropriate health care services. A wide variety of risky situations were attributed to the language barrier [8]. In the KSA, expatriates represent over $50 \%$ of the nursing staff in the kingdom [9]. In a study conducted in Riyadh-the capital of the Kingdom of Saudi Arabia (KSA), language barriers were perceived as a cause of workplace violence towards nurses [10].

Saudisation of all the workforce sectors including the health care is one of the 2030 goals in the KSAthat is increasing the percentage of Saudi nationals participating in the workforce and reducing of the percentage of expatriates. Despite the efforts to establish this goal, the nursing profession expatriate staff represents $50 \%$ of the nursing workforce [9]. Of note, the current situation reflects a significant increase in the proportion of Saudis in the nursing profession compared to the previous report which pointed out that Saudi nurses comprised only $29.1 \%$ of the total nursing workforce. But, the rate of Saudi nurses in private hospitals is remarkably low $(4.1 \%)[11,12]$. 
Improving the public image of nursing is fundamental in adopting a favorable nursing identity [13], while the poor image is likely to limit the consideration of nursing as a career choice $[14,15]$. In the UK, one report pointed to students' feelings of stress, not being valued, and having unmet expectations [16]. Cultural issues related to poor perception should be highlighted in order to implement focused intervention strategies to mitigate the consequences of this problem. For example, in the KSA one should consider that most Saudi families might discourage their daughters to enroll in jobs with gendermixed working environment [17].

Negative public image is influential for considering the nursing career as well as for retention of nurses in the nursing profession. Numerous studies highlighted the direct effect of the negative public image on a nurse's sense of identity [18-21]. A study in Saudi Arabia revealed that satisfaction of nurses is linked to a favorable nursing image [22]. In addition, the role of nursing institutions is vital in shaping the nursing identity. Freshmen nursing students mainly reflect the general viewpoint of society as they only have a limited understanding about nursing $[12,23,24]$. A study conducted in Turkey demonstrated that students didn't have sufficient knowledge regarding nursing at the beginning of their education; while an introduction to a nursing course has improved the students' understanding of the nursing profession [24]. Also, media projection about nursing could play a fundamental role to influence the public image of nursing [19].

Most of the published studies in Saudi Arabia were focused on nursing students and graduates $[17,18$, $21,22]$, with very limited data about the public image which is crucial if missing in shaping the nursing identity in the KSA. Hence, the main objective of this study is to explore the public image of nursing, and to determine the underlying factors that influence knowledge about the nursing profession, preference of caregivers, and perceived barriers to engage in a nursing career. Results would help to formulate intervention programs to improve the public image of the nursing profession, which will then be reflected in nursing identity, recruitment, and retention of Saudi nurses.

\section{Methods}

Subjects: Adult Saudi individuals of both genders were invited to participate in the current study.

Study settings: Princess Nora bint Abdulrahman University campus in Riyadh city. To portray the majority of the Saudi community, we included students enrolled in non-health colleges only. Because the campus includes only females, malls in Riyadh city were also approached to recruit adult volunteers of both genders. The variability in the socioeconomic status, age, and educational levels in mall visitors might better represent the community.

Study design: A cross-sectional study design was conducted that included 502 volunteers of both genders. A post-hoc power analysis revealed that a study of at least this size, assuming a prevalence of $50 \%$ negative perception, $7 \%$ allowable error in the estimate and $95 \%$ confidence, could detect differences with a power of 0.85 . 
Ethical issues: The current study was conducted in accordance with the Declaration of Helsinki; the study protocol was approved by the Ethical Review Boards of Princess Nourah bint Abdulrahman University, Riyadh, KSA. Participants were consented verbally and were informed that their participation is voluntary, the data are confidentiality, and that they can withdraw from the study at any point.

Data Collection: The researchers developed the questionnaire after a thorough review of the literature. It included the following sections; 1- sociodemographic data such as age, gender, education, and having a nurse in the family. Sections 2-4 were included items which could affect the public image about the nursing profession. The second section inquired about the preference of caregivers according to gender and nationality, rating of Saudi nursing skills, and stigma of the nursing profession. The third section was focused on knowledge about nursing education and the nursing profession; it included six multiple response questions, the correct answer scored as 1 , and the wrong answer scored as 0 . The total knowledge score equaled 6 . The fourth section addressed the perceived barriers to engage in a nursing career, and included seven questions structured on a Likert scales; the total perception score equaled 27. before application, the questionnaire was piloted on a sample of 20 individuals to determine the face validity, and necessary modifications were included. The final format was self-administered to volunteered participants.

Analysis of data: Data were checked for completeness and were analyzed using SPSS version 16.0. Percentages, mean, median, and interquartile range (IQR) were used to describe the data. Total score for knowledge and perceived barriers of data were calculated as a percentage of the maximum score. As the distribution of scores was not symmetric, so it was presented as median with inter-quartile-range (IQR). Group comparison in median score was performed using the nonparametric Mann-Whitney test for two groups and the Kruskal Wallis test for more than two groups. A $p$ value $<0.05$ was considered significant.

\section{Results}

The study encompassed 502 adult Saudis: 106 males (21.1\%) and 396 females (78.9\%), their mean age was $22.93 \pm 6.76$ with a median of 20 years. The majority were unmarried $(80.3 \%)$; overall, $74.3 \%$ were university educated (Table1). In general, $81.5 \%$ preferred female nurses, while only $32.5 \%$ preferred Saudis to provide nursing care. Among those who experienced Saudi caregivers, only $40.8 \%$ rate the service as excellent. Less than half of male participants reported that they would marry a nurse, and as much as $71 \%$ of the total sample would be ashamed if they have a nurse in their family (Table 2).

Regarding Knowledge about the nursing profession, as Table 3 shows, $61 \%$ of participants consider nursing as a subordinate to physicians. Moreover, knowledge about nursing careers was poor, as much as $68.9 \%$ didn't know that nurses often achieve higher managerial positions. About one-third of participants do not know the exact job title of graduates from nursing collegiate or programs. They don't even know the length of time required to acquire a bachelor degree. In total, the median knowledge score was only $50.0 \%$ of the maximum score. 
The median score of perceived barriers of the nursing profession was $52.38 \pm 10.93$. Differences in Language, and culture were perceived as barriers to get engaged in the nursing profession by $12 \%$ and $31.7 \%$ respectively. More than one third participants reported that mixed working environment is a barrier for nursing practice, and about one-fifth consider that being a female nurse will delay marriage. In addition, $64.5 \%$ of participants claim that nursing profession affects female social life negatively (Table 4).

Table 5 demonstrates factors associated with knowledge and perceived barriers regarding the nursing profession. Higher level of education, having a nurse in the family, and marriage are associated with a higher knowledge score. The perceived barrier score was higher among more educated individuals: $55.6 \%, 51.9 \%$, and $48.2 \%$ for graduates of high school, university versus those who just can read and write respectively. Also, the perceived barrier score was higher among those having a nurse in the family.

\section{Discussion}

The study revealed poor knowledge about the nursing profession and distrust in Saudi caregivers. Surprisingly, about one third only preferred to get the nursing care by Saudis. Moreover, the rating of Saudi caregivers was deemed excellent by only $40 \%$. In addition, nearly three quarters would be ashamed if they have a nurse in the family, and less than $50 \%$ of males prefer to marry a nurse. Also, the study highlighted numerous barriers including; mixed working environment, the delayed marriage of female nurses, and the negative effect of the nursing profession on social life.

The low preference for Saudi caregivers might reflect poor image and distrust in the national caregivers; this would be very distressing and de-motivating for Saudi nurses and for those who might consider a nursing career in the future. In addition, nearly three-quarters of participant agreed that they would be ashamed of having a nurse among their families. In accordance with our results, a Study in Saudi Arabia revealed that nursing as a childhood dream was not appealing, nor family support was influential [17]. Similarly, a study in China demonstrated that parents would not encourage their children to enroll in nursing education [25]. The observed positive perception of Omani university students about the nursing profession might reflect the overweight number of the nursing students in the study compared to students from other disciplines [26]. Secondly, other factors concerning the heath care policies to recruit nationals and media marketing of the nursing profession in Oman should not be ignored.

However, the preference of the study participants of females as caregivers stems from the perception that nursing is women's occupation. In addition, cultural norms reject getting care by opposite gender especially for females.

Regarding the level of knowledge about the nursing profession, it is striking that most of participants in the present study viewed the role of nursing in health care settings as complementary to physicians, and about one third do not know the exact job title of graduates from nursing college or institutes. Additionally, they don't know even the duration required to get a bachelor degree in nursing according to the Saudi nursing institutions. Previous studies confirmed the perceived attenuated role of nurses 
compared to physicians. These negative stereotypes view nurses as having no status and describe them as physicians' assistants and ancillary workers $[23,25,27]$. A study from Iran view nurses as having no status and described them as physicians' assistants and auxiliary workers [19]. In this study, students emphasized that the social status of nurses is not desirable, as they are considered handmaidens of physicians and dutiful hospital employees. Another student mentioned: "although nurses are sometimes perceived as educated, their main task is to obey and follow physicians' orders and their caring skills are not appreciated" [19].

Similarly, a recent study in Saudi Arabia which included over 700 participants of both genders, revealed that more than one-third of participants perceive nursing as a profession that is auxiliary and subservient to physicians, and therefore no need for higher academic qualifications [17]. This means that the community in Saudi Arabia doesn't value the skills and competencies acquired through higher academic education.

Despite the sincere efforts of Saudization of the workforce in the KSA, expatriates remain to constitute a considerable proportion of the nursing workforce [22]. Saudi culture may regard the nursing profession unfavorable work atmosphere and hence discourage their children to pursue a nursing career The present study revealed that a considerable proportion of the study sample (64.5\%) claim negative consequences of nursing on social life probably because of long working hours and night shifts, other barriers include delayed marriage and gender-mixed working environment. The observation that the overall perceived barrier score was significantly lower among less educated must be interpreted with caution.

It is likely that the global image of the nursing profession is negative. Previous studies demonstrated that nursing is viewed as a less desirable profession because of difficult working conditions, inadequate financial compensation, low level of autonomy, limited career opportunities, and being viewed as ancillary members of the healthcare team [21, 28].

Finally, this study demonstrates the community level of knowledge about the nursing career and reflects the public image of the nursing profession. Such information is paramount for effective interventions to raise community awareness and modify the negative image of the nursing profession. Hopefully, the nursing identity will be improved leading to recruitment of high achievers and retention of candidates into the nursing career.

\section{Limitations of the study}

Limited generalizability of the study results because of the study settings, as the study was conducted in a big city-the capital of Saudi Arabia, while sub-urban and rural communities are not represented. The convenient sampling technique, and the unequal gender representation are another limitations.

\section{Conclusions}


The study revealed poor knowledge and misinformation about what nurses can do and what professional position they can achieve. In addition, the study highlighted a number of including working in a mixed working environment; delayed marriage of females, and poor social life. These findings from the stakeholders are crucial to implementing focused intervention strategies in the future to improve the public perception of nursing in the KSA.

\section{Declarations}

\section{Acknowledgment}

The authors acknowledge the study participants for their time and patience to volunteer in the study.

\section{Authors contributions}

HE Conceived the study idea and designed the study and drafted the manuscript. AO Collected the data and participated in the data entry and analysis. MH Contributed to the study design and analyzed the data. SA Critically reviewed and revised the manuscript. All authors read and approved the final manuscript.

\section{Funding}

This research was funded by the Deanship of Scientific Research at princess Nourah bint Abdulrahman University through the Fast-track Research Funding Program.

\section{Conflict of interest}

The authors declare that they have no competing interests.

\section{Availability of data and materials}

The datasets used analyzed during the current study are available from the corresponding author on reasonable request.

\section{References}

1. Canada H: A Report on the Nursing Strategy for Canada. In.; 2003.

2. Price SL, McGillis Hall L: The history of nurse imagery and the implications for recruitment: a discussion paper. Journal of advanced nursing 2014, 70(7):1502-1509.

3. Price S: Future directions for career choice research in nursing: a discussion paper. International journal of nursing studies 2009, 46(2):268-276.

4. Westendorf $\mathrm{JJ}$ : The nursing shortage: recruitment and retention of current and future nurses. Plastic surgical nursing : official journal of the American Society of Plastic and Reconstructive Surgical Nurses 2007, 27(2):93-97. 
5. Buchan J: Nurses moving across borders: 'brain drain' or freedom of movement? International nursing review 2001, 48(2):65-67.

6. Aiken LH, Clarke SP, Silber JH, Sloane D: Hospital nurse staffing, education, and patient mortality. LDI issue brief 2003, 9(2):1-4.

7. Aiken LH, Clarke SP, Sloane DM: Hospital restructuring: does it adversely affect care and outcomes? Journal of health and human services administration 2001, 23(4):416-442.

8. van Rosse F, de Bruijne M, Suurmond J, Essink-Bot ML, Wagner C: Language barriers and patient safety risks in hospital care. A mixed methods study. International journal of nursing studies 2016, 54:45-53.

9. MOH: Health Statistical Year Book, Statistical Division, MOH, Riyadh In. Saudi Arabia; 2012.

10. Mohamed AG: Work-related assaults on nursing staff in riyadh, saudi arabia. Journal of family \& community medicine 2002, 9(3):51-56.

11. Annual Report, Ministry of Health, KSA 1429 [WWW.moh.gov.sa/ statistics/ s2008/2008. Html]

12. Almalki M, FitzGerald G, Clark M: The nursing profession in Saudi Arabia: an overview. International nursing review 2011, 58(3):304-311.

13. Johnson M, Cowin LS, Wilson I, Young H: Professional identity and nursing: contemporary theoretical developments and future research challenges. International nursing review 2012, 59(4):562-569.

14. Tierney MJ, Tierney LM, Jr.: Nursing in Japan. Nursing outlook 1994, 42(5):210-213.

15. Katsuragi S: Better working conditions won by 'nurse wave' action: Japanese nurses' experience of getting a new law by their militant campaign. Nursing ethics 1997, 4(4):313-322.

16. Last L, Fulbrook P: Why do student nurses leave? Suggestions from a Delphi study. Nurse education today 2003, 23(6):449-458.

17. Alboliteeh M, Magarey J, Wiechula R: The Profile of Saudi Nursing Workforce: A Cross-Sectional Study. Nursing research and practice 2017, 2017:1710686.

18. Almutairi AF, McCarthy A, Gardner GE: Understanding cultural competence in a multicultural nursing workforce: registered nurses' experience in Saudi Arabia. J Transcult Nurs 2015, 26(1):16-23.

19. Nikbakht Nasrabadi A, Emami A: Perceptions of nursing practice in Iran. Nursing outlook 2006, 54(6):320-327.

20. Cook TH, Gilmer MJ, Bess CJ: Beginning students' definitions of nursing: an inductive framework of professional identity. The Journal of nursing education 2003, 42(7):311-317.

21. Jackson CL, Gary R: Nursing: Attitudes, perceptions and strategies for progress in Saudi Arabia. Annals of Saudi medicine 1991, 11(4):452-458.

22. Alotaibi J, Paliadelis PS, Valenzuela FR: Factors that affect the job satisfaction of Saudi Arabian nurses. Journal of nursing management 2016, 24(3):275-282.

23. Girvin J, Jackson D, Hutchinson M: Contemporary public perceptions of nursing: a systematic review and narrative synthesis of the international research evidence. Journal of nursing management 
2016, 24(8):994-1006.

24. Karaoz S: Change in nursing students' perceptions of nursing during their education: the role of the Introduction to Nursing course in this change. Nurse education today 2004, 24(2):128-135.

25. ten Hoeve Y, Jansen G, Roodbol P: The nursing profession: public image, self-concept and professional identity. A discussion paper. Journal of advanced nursing 2014, 70(2):295-309.

26. Shukri RK, Bakkar BS, El-Damen MA, Ahmed SM: Attitudes of Students at Sultan Qaboos University towards the Nursing Profession. Sultan Qaboos University medical journal 2013, 13(4):539-544.

27. Neilson GR, Lauder W: What do high academic achieving school pupils really think about a career in nursing: analysis of the narrative from paradigmatic case interviews. Nurse education today 2008, 28(6):680-690.

28. Racic M, Pavlovic J, Hadzivukovic N, Ivkovic N: Perceptions, attitudes, and expectation of baccalaureate nurses toward position of nursing in Bosnia and Herzegovina. The International journal of health planning and management 2019, 34(2):e1223-e1235.

\section{Tables}

Table 1. Distribution of the study sample according sociodemographic characteristics 


\begin{tabular}{|c|c|c|c|}
\hline \multicolumn{2}{|c|}{ Sociodemographic characteristics, $n=502$} & \multicolumn{2}{|c|}{$\%$} \\
\hline \multirow[t]{2}{*}{ Sex } & Male & 106 & 21.1 \\
\hline & Female & 396 & 78.9 \\
\hline \multirow[t]{4}{*}{ Age } & $15-$ & 166 & 33.1 \\
\hline & $20-$ & 223 & 44.4 \\
\hline & $25+$ & 113 & 22.5 \\
\hline & Mean \pm SD & $22.9 \pm 6.8$ & - \\
\hline \multirow[t]{2}{*}{ Marital status } & Married & 99 & 19.7 \\
\hline & Unmarried & 403 & 80.3 \\
\hline \multirow[t]{3}{*}{ Education } & Below secondary & 23 & 4.6 \\
\hline & Secondary (High school) & 106 & 21.1 \\
\hline & University or higher & 373 & 74.3 \\
\hline \multirow[t]{2}{*}{ House } & Private & 352 & 70.1 \\
\hline & Rented & 150 & 29.9 \\
\hline \multirow[t]{2}{*}{ Female nurse in the family } & Yes & 149 & 29.7 \\
\hline & No & 353 & 70.3 \\
\hline
\end{tabular}

SD: Standard deviation.

Table 2. Preferences of nursing care and stigma of the nursing profession $(N=502)$ 


\begin{tabular}{|c|c|c|c|}
\hline Question & Response & No. & $\%$ \\
\hline \multirow[b]{2}{*}{ Preference of care giver according to gender } & Male nurse & 93 & 18.5 \\
\hline & Female nurse & 409 & 81.5 \\
\hline \multirow[t]{3}{*}{ Preference of care giver according to nationality } & Saudi & 163 & 32.5 \\
\hline & Non-Saudi & 102 & 20.3 \\
\hline & Never mind & 237 & 47.2 \\
\hline \multirow[t]{2}{*}{ Getting care by Saudi females } & Yes & 299 & 59.6 \\
\hline & No & 203 & 40.4 \\
\hline \multirow[t]{4}{*}{ Rating of Saudi female nursing care* } & Excellent & 122 & 40.8 \\
\hline & Very good & 112 & 37.5 \\
\hline & Good & 55 & 18.4 \\
\hline & Bad & 10 & 3.3 \\
\hline \multirow{5}{*}{$\begin{array}{l}\text { Stigma of nursing } \\
\text { (ashamed to have a nurse in my family) }\end{array}$} & Strongly agree & 246 & 49.0 \\
\hline & Agree & 113 & 22.5 \\
\hline & Neutral & 84 & 16.7 \\
\hline & Disagree & 36 & 7.2 \\
\hline & Strongly disagree & 23 & 4.6 \\
\hline \multirow[t]{2}{*}{ Preference to marry a female nurse** } & Yes & 46 & 43.4 \\
\hline & No & 60 & 56.6 \\
\hline
\end{tabular}

*Asked to those who received care by Saudi female nurses (299) **Asked to males only.

Table 3. Knowledge about the nursing profession $(\mathrm{N}=502)$ 


\begin{tabular}{|c|c|c|c|}
\hline \multicolumn{2}{|l|}{ Knowledge Item } & \multicolumn{2}{|c|}{ No. $\%$} \\
\hline \multirow[t]{3}{*}{ Nursing duties } & Provide medical care, follow-up and health & 196 & $39 \%$ \\
\hline & education & & \\
\hline & Complementary to physician & 306 & 61.0 \\
\hline \multirow[t]{3}{*}{ Job title of graduates of nursing institutes } & Nurse specialist & 67 & 13.3 \\
\hline & Technical nurse & 249 & 49.6 \\
\hline & Don't know & 186 & 37.1 \\
\hline \multirow[t]{3}{*}{ Job title of graduates of bachelor program } & Nurse specialist & 286 & 57.0 \\
\hline & Technical nurse & 52 & 10.4 \\
\hline & Don't know & 164 & 32.7 \\
\hline \multirow{5}{*}{$\begin{array}{l}\text { Duration of bachelor degree (Including } \\
\text { internship) }\end{array}$} & Two years & 22 & 4.4 \\
\hline & Three & 54 & 10.8 \\
\hline & Four & 97 & 19.3 \\
\hline & Five & 152 & 30.3 \\
\hline & Don't know & 177 & 35.3 \\
\hline \multirow[t]{2}{*}{ Nursing has several specialties } & Yes & 387 & 77.1 \\
\hline & No & 115 & 22.9 \\
\hline \multirow{2}{*}{$\begin{array}{l}\text { A nurse can be promoted to a hospital } \\
\text { manager }\end{array}$} & Yes & 156 & 31.1 \\
\hline & No & 346 & 68.9 \\
\hline \multicolumn{2}{|l|}{ *Total score as \% of maximum, median (IQR) } & & \\
\hline
\end{tabular}

*Score range 0-6 (0-100\% of maximum), higher score indicates better knowledge

*IQR $=$ inter-quartile-range

Table 4: Perceived barriers of public to engagement in the nursing profession, $n=502$ 


\begin{tabular}{|c|c|c|c|c|c|c|c|c|c|c|}
\hline \multirow[t]{2}{*}{ Perceived barriers } & \multicolumn{2}{|c|}{$\begin{array}{l}\text { Strongly } \\
\text { agree }\end{array}$} & \multicolumn{2}{|c|}{ Agree } & \multicolumn{2}{|c|}{ Neutral } & \multicolumn{2}{|c|}{ Disagree } & \multicolumn{2}{|c|}{$\begin{array}{l}\text { Strongly } \\
\text { disagree }\end{array}$} \\
\hline & No. & $\%$ & No. & $\%$ & No. & $\%$ & No. & $\%$ & No. & $\%$ \\
\hline $\begin{array}{l}\text { Communication with different } \\
\text { language }\end{array}$ & 9 & 1.8 & 51 & 10.2 & 100 & 19.9 & 148 & 29.5 & 194 & 38.6 \\
\hline $\begin{array}{l}\text { Communication with different } \\
\text { culture }\end{array}$ & 45 & 9.0 & 114 & 22.7 & 121 & 24.1 & 109 & 21.7 & 113 & 22.5 \\
\hline $\begin{array}{l}\text { Being Saudi is viewed as a skilled } \\
\text { nurse* }\end{array}$ & 9 & 1.8 & 32 & 6.4 & 179 & 35.7 & 150 & 29.9 & 132 & 26.3 \\
\hline $\begin{array}{l}\text { Poor public image of nursing } \\
\text { profession }\end{array}$ & 43 & 8.6 & 54 & 10.8 & 74 & 14.7 & 161 & 32.1 & 170 & 33.9 \\
\hline Mixed working environment & 60 & 12.0 & 120 & 23.9 & 55 & 11.0 & 118 & 23.5 & 149 & 29.7 \\
\hline $\begin{array}{l}\text { Delayed marriage of a female } \\
\text { nurse }\end{array}$ & 35 & 7.0 & 67 & 13.3 & 107 & 21.3 & 150 & 29.9 & 143 & 28.5 \\
\hline Nursing profession affects female & \multicolumn{2}{|c|}{ Extremely } & \multicolumn{2}{|c|}{ Moderately } & \multicolumn{3}{|c|}{ Marginally } & \multicolumn{3}{|c|}{ Not at all } \\
\hline social life & 84 & 16.7 & 240 & 47.8 & 12 & & & 5 & & 10.0 \\
\hline $\begin{array}{l}\text { **Total score as } \% \text { of maximum, } \\
\text { median (IQR) }\end{array}$ & & & & & 51.85 & $4.44-$ & .26) & & & \\
\hline
\end{tabular}

*Reverse score order **Score range 0-27**IQR: Interquartile range

Table 5. Association between sociodemographic characteristics, knowledge and perceived barriers of the nursing profession $(\mathrm{N}=502)$ 


\begin{tabular}{|c|c|c|c|c|c|}
\hline \multicolumn{2}{|l|}{ Sample characteristics } & \multicolumn{2}{|l|}{ knowledge } & \multicolumn{2}{|c|}{ Perceived barriers } \\
\hline & & $\begin{array}{l}\text { Median } \\
\text { (IQR) }\end{array}$ & $P^{f}$ & $\begin{array}{l}\text { Median } \\
\text { (IQR) }\end{array}$ & $P^{f}$ \\
\hline \multirow[t]{2}{*}{ Sex } & Male & $\begin{array}{c}66.7 \\
(50.0-83.3)\end{array}$ & \multirow[t]{2}{*}{0.126} & $\begin{array}{c}51.9 \\
(44.4-59.3)\end{array}$ & \multirow[t]{2}{*}{0.863} \\
\hline & Female & $\begin{array}{c}50.0 \\
(50.0-66.7)\end{array}$ & & $\begin{array}{c}51.9 \\
(44.4-59.3)\end{array}$ & \\
\hline \multirow[t]{3}{*}{ Age (years) } & $15-$ & $\begin{array}{c}50.0 \\
(33.3-66.7)\end{array}$ & \multirow[t]{3}{*}{0.069} & $\begin{array}{c}51.9 \\
(44.4-59.3)\end{array}$ & \multirow[t]{3}{*}{0.881} \\
\hline & $20-$ & $\begin{array}{c}50.0 \\
(50.0-66.7)\end{array}$ & & $\begin{array}{c}51.9 \\
(44.4-59.3)\end{array}$ & \\
\hline & $25+$ & $\begin{array}{c}66.7 \\
(50.0-83.3)\end{array}$ & & $\begin{array}{c}51.9 \\
(44.4-59.3)\end{array}$ & \\
\hline \multirow[t]{2}{*}{ Marital status } & Married & $\begin{array}{c}66.7 \\
(50.0-83.3)\end{array}$ & \multirow[t]{2}{*}{$0.001 *$} & $\begin{array}{c}51.9 \\
(44.4-59.3)\end{array}$ & \multirow[t]{2}{*}{0.225} \\
\hline & Unmarried & $\begin{array}{c}50.0 \\
(33.3-66.7)\end{array}$ & & $\begin{array}{c}51.9 \\
(44.4-59.3)\end{array}$ & \\
\hline \multirow[t]{3}{*}{ Education } & Read \& write & $\begin{array}{c}50.0 \\
(33.3-66.7)\end{array}$ & \multirow[t]{3}{*}{$0.001 *$} & $\begin{array}{c}48.2 \\
(48.2-59.3)\end{array}$ & \multirow[t]{3}{*}{$0.043^{*}$} \\
\hline & High school & $\begin{array}{c}50.0 \\
(33.3-66.7)\end{array}$ & & $\begin{array}{c}55.6 \\
(48.2-63.0)\end{array}$ & \\
\hline & University and higher & $\begin{array}{c}66.7 \\
(50.0-66.7)\end{array}$ & & $\begin{array}{c}51.9 \\
(44.4-59.3)\end{array}$ & \\
\hline \multirow[t]{2}{*}{ House } & Private & $\begin{array}{c}50.0 \\
(50.0-66.7)\end{array}$ & \multirow[t]{2}{*}{0.541} & $\begin{array}{c}51.9 \\
(44.4-59.3)\end{array}$ & \multirow[t]{2}{*}{0.704} \\
\hline & Rented & $\begin{array}{c}66.7 \\
(33.3-66.7)\end{array}$ & & $\begin{array}{c}51.9 \\
(44.4-59.3)\end{array}$ & \\
\hline Female nurse in the family & Yes & $\begin{array}{c}66.7 \\
(50.0-66.7)\end{array}$ & $0.046^{*}$ & $\begin{array}{c}55.6 \\
(48.2-63.0)\end{array}$ & $0.032 *$ \\
\hline
\end{tabular}




\begin{tabular}{|l|l|c|c|c|} 
& No & 50.0 & & 51.9 \\
$(33.3-66.7)$ & & $(44.4-59.3)$ & \\
\hline
\end{tabular}

f Mann-Whitney test for two groups and Kruskal-Wallis test for more than two groups $* \mathrm{P}<0.05$ (Significant) 